\title{
Multispectral images of peach related to firmness and maturity at harvest
}

\author{
L. Lleó ，P. Barreiro , M. Ruiz-Altisent , A. Herrero \\ Universidad Politếcnica de Madrid, Departamento de Ciencia y Tecnologias Aplicadas a la Ingeniería Têcnica Agrícola, c/Cindad Universitaria s/n, \\ E. U. I. T. A., 28040 Edificio, Madrid, Spain \\ Physical Properties and Advanced Techniques in Agrofood, LPF-TAG Rural Engineering Dept, Politechnic University of Madrid, c/Ciudad Universitaria s/n, \\ Edificio de Motores y Máquinas, Departamento de Ingenieria Rural, E.T.S.J.A., Universidad Politécnica de Madrid, UPM. 28040, Madrid, Spain
}

\author{
Keywords: \\ Fruit \\ Multispectral \\ Vision \\ Ripeness \\ Firmness \\ Maturity \\ Non-destructive \\ Quality \\ Visible spectra \\ Chlorophyll \\ Peach
}

\begin{abstract}
A B S T R A T
Two multispectral maturity classifications for red soft-flesh peaches ('Kingcrest'. 'Rubyrich' and 'Richlady' $n=260$ ) are proposed and compared based on $R$ (red) and R/IR (red divided by infrared) images obtained with a three CCD camera ( $800 \mathrm{~nm}, 675 \mathrm{~nm}$ and $450 \mathrm{~nm}$ ). R/IR histograms were able to correct the effect of 3D shape on light reflectance and thus more Gaussian histograms were produced than R images. As fruits ripened, the R/IR histograms showed increasing levels of intensity. Reference measurements such as firmness and visible spectra also varied significantly as the fruit ripens, firmness decreased while reflectance at $680 \mathrm{~nm}$ increased (chlorophyll absorption peak).
\end{abstract}

\section{Introduction}

A major issue in designing vision systems for maturity assessment in fruits is the identification of the most relevant wavelengths for this goal. For monitoring ripening of peaches, reflectance at $450 \mathrm{~nm}$ and $680 \mathrm{~nm}$ can provide complementary information (Ruiz-Altisent et al., 2006). In the visible range, two areas have been addressed as the most important areas: $680 \mathrm{~nm}$ related to chlorophyll content, and $\mathbf{4 5 0} \mathrm{nm}$ related to carotenoids content. Ruiz-Altisent et al. (2006) showed that both groups of pigments evolve independently for commercial peach varieties, also providing very different ranges of variation. Several research results have considered the chlorophyll band (Tu et al., 1995 cited by $\mathrm{Lu}$ (2004), Lu and Peng (2006)) or water absorbance band (Mc McGlone et al., 1997 cited by Lu (2004)) as most relevant for maturity and firmness. Reflectance at $680 \mathrm{~nm}$, related to chlorophyll content, presented the highest correlation with firmness in peach (Lu and Peng, 2006).
Differences can be found between (a) selecting narrow wavelengths as light sources while using standard panchromatic CCD cameras and (b) the use of panchromatic light with narrow filters for image acquisition. Thus, Tu et al. (1995) used He-Ne laser as a light source at $670 \mathrm{~nm}$ in peach and McGlone et al. (1997) used a diode laser at $864 \mathrm{~nm}$ as light source in kiwifruit. Instead, Lu and Peng (2006) made use of panchromatic light source.

Multispectral imaging is a technology originally developed for space-based imaging which may capture light from wavelengths beyond the visible light range, such as infrared, allowing the extraction of additional information that the human eye fails to capture. Multispectral imaging can be used to address external features such as ripening (Lu, 2004) and external defects (Diaz et al., 2000, 2004; Leemans and Destain, 2004; Kleynen et al., 2003; Melı] et al., 2004: Tao and Wen, 1999; Singh and Delwiche, 1994; Unay and Gosselin, 2006) with higher sensitivity in comparison to the ordinary RGB imaging (Gómez-Sanchís et al., 2008; Aleixos et al., 2002, 2007; Leemans et al., 2002; Kleynen et al., 2003).

RGB vision is a simplified case of multispectral imaging, where broad wavelength ranges are used. Aleixos et al. (2002) described an on-line image system for sorting oranges which used an RGB camera together with a $750 \mathrm{~nm}$ image. Defect regions were detected, and ripeness was estimated using Bayesian discriminant 
algorithms. Laykin et al. (2002) used different algorithms that were applied to classify tomatoes employing RGB cameras, based on colour, defects and colour homogeneity. Also in tomatoes, Jahns et al. (2001) found that the dominating wavelength calculated from RGB images increases for increasing maturity, and that a significant negative correlation was found between firmness stage (elasticity modulus) and such dominant wavelength. Sugar content of lyokan orange was estimated $\left(R^{2}=0.6\right)$ by means of neural networks by making use of colour, shape and roughness extracted from RGB images by Kondo et al. (2000).

When using several wavelengths for multispectral applications, the definition of ratios is a key target. Reflectance ratio $670 \mathrm{~nm} /$ $800 \mathrm{~nm}$ was earlier shown to be a good maturity index for sorting yellow clingstone peaches (Delwiche et al., 1987). The main advantage of using ratios is the compensation of lighting changes and shape effects. The Normalized Difference Vegetation Index NDVI = (R800-R680)/(R800 + R680) that uses two spectral bands, 680 and $800 \mathrm{~nm}$, is a parameter that has shown to compensate such changes even for very large lighting changes, such as those registered under remote sensing. The NDVl can be used for chlorophyll content estimation in the image system presented by Vila et al. (2005).

The reference properties that are used as a base for comparison towards vision systems are mainly firmness and soluble solids content. Light backscattering has been related to firmness in several types of research in apple and peach. Lu (2004) used multispectral images at five spectral bands between $680 \mathrm{~nm}$ and $1060 \mathrm{~nm}$, selected on literature review, to quantify light backscattering profiles of apple fruit for predicting firmness and soluble solids content. Using neural network methods, three different ratios that made use of four wavelengths gave the best predictions of fruit firmness. When only one ratio was used, $680 \mathrm{~nm} / 940 \mathrm{~nm}$ gave the best firmness prediction. Tu et al. (1995) cited by lu (2004) recorded reflectance images at $670 \mathrm{~nm}$ in peach. As firmness decreased, the red band histogram moved to the right, i.e. the intensity of the light reflected by the fruit increased as firmness decreased. McGlone et al. (1997) cited by Lu (2004) reported that the intensity of light emitted from the kiwifruit increased with decreasing firmness. Furthermore, Peng and Lu (2006) compared three mathematical models for scattering profiles in apples in order to improve firmness estimation. Qing et al. (2007) employed laser-induced backscattering light to predict soluble solids content and firmness in apples. Related to peach, Lu and Peng (2006) found that the backscattered light at $677 \mathrm{~nm}$, characterised by four parameters extracted from its corresponding 'Lorentzian' profile, and also around $677 \mathrm{~nm}$. had the highest correlation with peach firmness, using halogen lamp as light source. They also found that the region around one water absorption peak $(950 \mathrm{~nm})$ showed some correlation with firmness in some cultivars. Carlomagno et al. (2004) used a spectrograph in combination with a CCD camera analyzing the spectrum transmitted by peaches (detector positioned $120^{\circ}$ with respect to the light) in the near infrared (730-900 nm). After denoising the signal, peaches were sorted based on their degree of ripeness, in terms of sugar content and firmness, with a minimum distance classifier method, obtaining $82.5 \%$ of correct classification with respect to the previous established classes.

Most recent developments concerning image analysis in the food industry have been shown by Du and Sun (2006) and Zheng et al. (2006). Applications of different colour spaces for food quality evaluation were reviewed. Du and Sun (2006) presented the recent advances in learning techniques for food quality evaluation based on computer vision. In the case of fruits, the statistics learning is employed for segmentation, feature extraction and defects classification: Bayesian classification process, Bayesian and linear discriminant analysis together with Mahalanobis distance classifiers (Kleynen et al., 2003; Diaz et al., 2000, 2004).
The main objective of the present work was to test the ability of multispectral images at two specific wavelengths $680 \mathrm{~nm}$ and $800 \mathrm{~nm}$ ) to classify peaches into maturity categories and to compare such classification with regard to reference measurements such as firmness and reflectance at $680 \mathrm{~nm}$ achieved with a visible spectrometer. For this, these images were achieved with a three CCD camera using narrow bandwidth filters centred at $450 \mathrm{~nm}$. $680 \mathrm{~nm}$ and $800 \mathrm{~nm}$. The results corresponding to $680 \mathrm{~nm}$ and $800 \mathrm{~nm}$ are the ones presented in this work.

\section{Materials and methods}

\subsection{Materials}

Three cultivars of red soft-flesh peaches ('Kingcrest', 'RubyRich' and 'Richlady') were analyzed (260 fruits, 2 replicates per fruit, from a variety of maturity stages collected at harvest). Samples ( $n=30-40$ fruits) were randomly selected from just-harvested fruits in a number of Murcia cooperatives, so that the whole maturity range was represented. Each sample was harvested on the same date, and was obtained from the same orchard. Samples were then sent to Madrid in refrigerated, isothermic boxes and after $12 \mathrm{~h}$ the temperature was increased $\left(20^{\circ} \mathrm{C}\right)$ for $4-5 \mathrm{~h}$, and the fruit was then ready for experimentation.

\subsection{Reference and multispectral measurements}

Non-destructive reference tests (contact firmness and reflectance spectrometry) and images acquisition were applied to $100 \%$ of the fruits, while destructive reference tests (Magness-Taylor firmness and soluble solids content SSC) were carried out on $75 \%$ of fruits. Reference tests were used to compare with the classifications based on the images obtained with the multispectral system. All measurements were carried out on both sides of the fruit (the most coloured side 'blush' and the opposite side 'ground'). Reference parameters were measured in the following order:

Contact firmness. Measured by means of Impactor response, the maximum impact acceleration $\left(\mathrm{m} / \mathrm{s}^{2}\right)$ and duration (ms) were measured using the 'LPF-Lateral Impact Sensor 2.0' furnished with a piezoelectric accelerometer ENDEVCO model 256-10 (ENDEVCO, SAN JUAN CAPISTRANO, CA 92675 USA); which was adapted for on-line use by Garcia-Ramos et al. (2003). Measurements were carried out in triplicate on each side of the fruit samples.

Optical reflectance. Visible relative reflectance spectra were obtained with a portable spectrophotometer Minolta CM-50) (Konica Minolta Sensing, lnc., Japan), 450-700 nm, at 30-nm intervals. Selected wavelength values at $450 \mathrm{~nm}(\mathrm{R} 450)$ and at $680 \mathrm{~nm}(\mathrm{R} 680)$ were used as a reference with regard to multispectral information. Two measurements were taken on each fruit, one on each side.

Fimness. Maximum penetration force, Magness-Taylor (firmness), in $\mathrm{N}$, and force/deformation ratio (hardness), in $\mathrm{N} / \mathrm{mm}$, were measured using a force/deformation resistance meter, with an $8-\mathrm{mm}$ diameter rod, at a deformation rate of $20 \mathrm{~mm} / \mathrm{min}$ using a Texture Analyzer XT2 (Stable Micro Systems Ltd., Godalming, UK). Measurements were taken on both sides of the fruit.

Soluble solids SS, measured in ${ }^{\circ}$ Brix, on a few drops of juice with a digital refractometer ATAGO PR-101 (ATAGO CO., LTD, USA). SS are correlated with the sweetness of peaches and basically consist of sucrose, glucose and fructose. The $S S$ content was measured on both sides of each fruit.

Spectral imaging. The imaging system consisted of a framegrabber, National Instruments ${ }^{\text {}}$, and a three CCD custom camera, DuncanTech/Redlake MS-3100 (Redlake Inc., USA) with three bandpass filters centred at $800 \mathrm{~nm}$ Infrared (IR), $675 \mathrm{~nm}$ Red (R) and $450 \mathrm{~nm}$ Blue (B), with a bandwidth of $20 \mathrm{~nm}$. The selection of these 
spectral bands was based on the previous research (Ruiz-Altisent et al., 2006) and also on several optical indices extracted from the literature (Zude, 2003; Merzlyak et al., 2003; Delwiche et al., 1987).

The light source was provided by six $100 \mathrm{~W}$ halogen lamps.

Statistical analysis. The reference measurements were compared with the classifications based on the histograms of the images (Section 2.3.). One image was acquired from each side of the fruit. Non-supervised (Ward) classifications of fruits were carried out, made on both the individual varieties and the pooled samples. ANOVA was applied to the reference parameters and to the data extracted from the image analysis. The analysis of the images and data (Ward classification algorithm, ANOVA, regressions) was carried out using Matlab ${ }^{\star}$ (version 7.0; Math Works, Inc., USA) and Statistica ${ }^{(B)}$ (version 6, StatSoft, Inc., Tulsa, Oklahoma, USA).

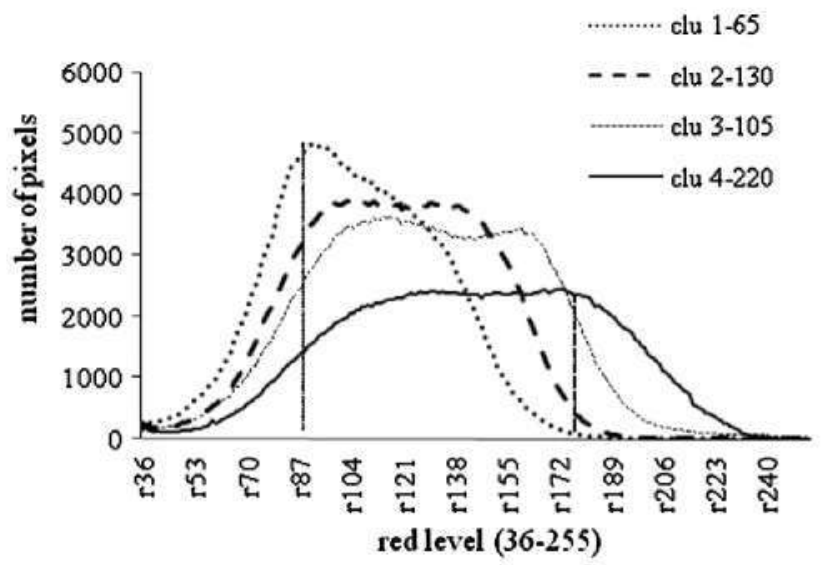

Fig. 1. Average red histogram for each cluster with the number of fruits for each. Vertical lines indicate the range of largest variation of the average histograms. From left to right, cluster 1 , cluster 2 , cluster 3 and cluster 4 average histograms. (Increasing maturity stage from 1 to 4 ).

\subsection{Image analysis. Non-supervised classifications based on histograms}

Two non-supervised classifications based on the Ward method (Ward, 1963) were applied and compared to each other and to the reference measurements. Both classifications were applied on the histograms extracted from the region of interest, i.e. the skin of the peach. Ward method is a step by step agglomerative method that minimizes the intra variance of a group or cluster. Therefore, a cluster is a group of samples with similar characteristics. The Ward method finds at each step these two clusters whose pooling gives the minimum increase in the within group sum of squares. The Euclidean distance between each datum and the corresponding centroid of the group was used to calculate such sum of squares. In the present work, two images were acquired per fruit, one from each side. The classifications were applied to all images (i.e. two images per fruit were acquired considering blush and ground colour sides; 260 fruits, 520 images). By studying the resulting dendrogram (not shown) with linkage distances between clusters, four clusters were considered in both non-supervised classifications presented. Once all the histograms for the four cultivars were grouped into the four clusters, the average histogram was calculated for each cluster.

The first classification considered the red channel images and grey levels ranging from 36 to 255 , which corresponded to the values above the segmentation threshold of fruit with regard to the background.

The second classification employed the histograms of the Red/ InfraRed images, corresponding to the peach. Previously the fruit was segmented from the background, by employing the Infrared images as threshold (under the particular illumination and acquisition conditions, fruits always corresponded to grey levels higher than 55 in every case). Internal validation of the Red/InfraRed images classification was performed by means of the calculus of the Euclidean distance between each anonymous histogram and the corresponding average of the four clusters. Each histogram was assigned to the cluster whose distance is the minimum of the four clusters.

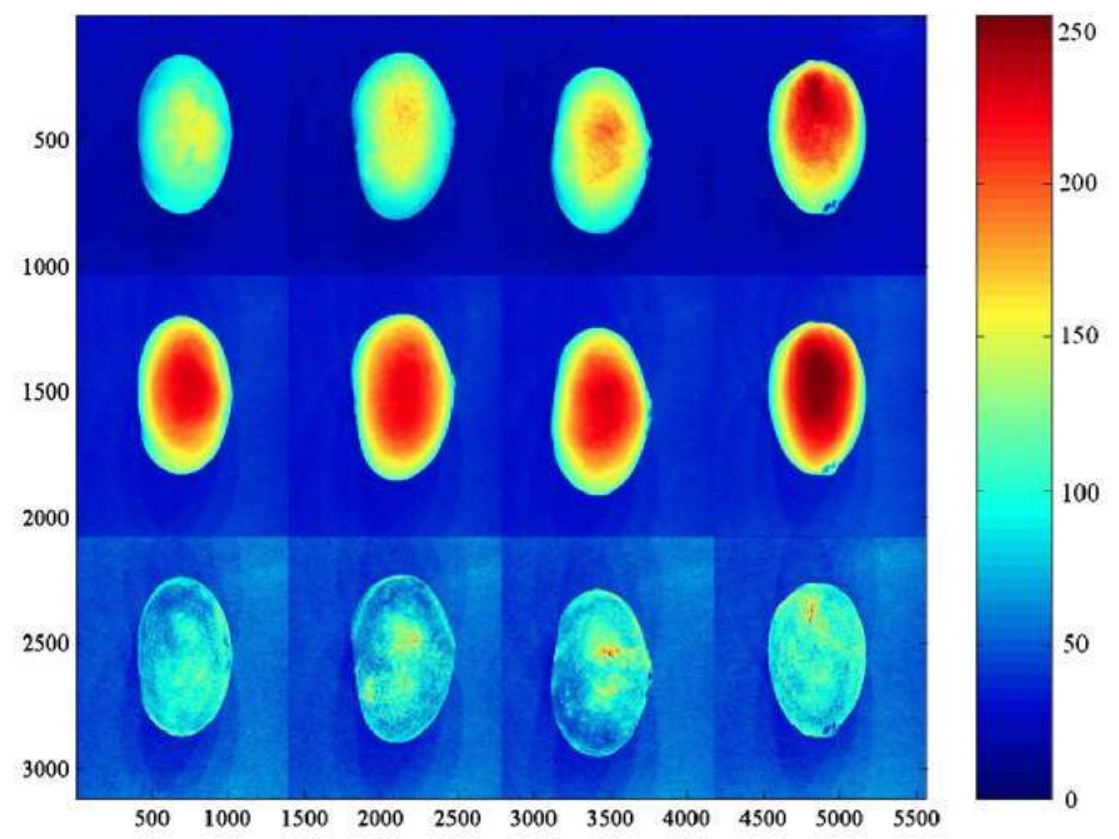

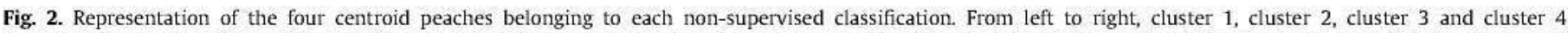

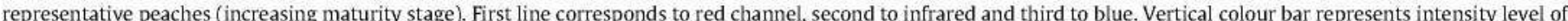

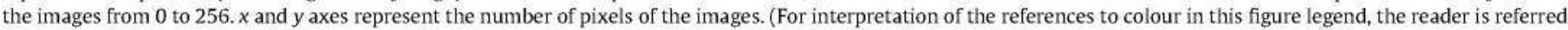
to the web version of this article.) 
a
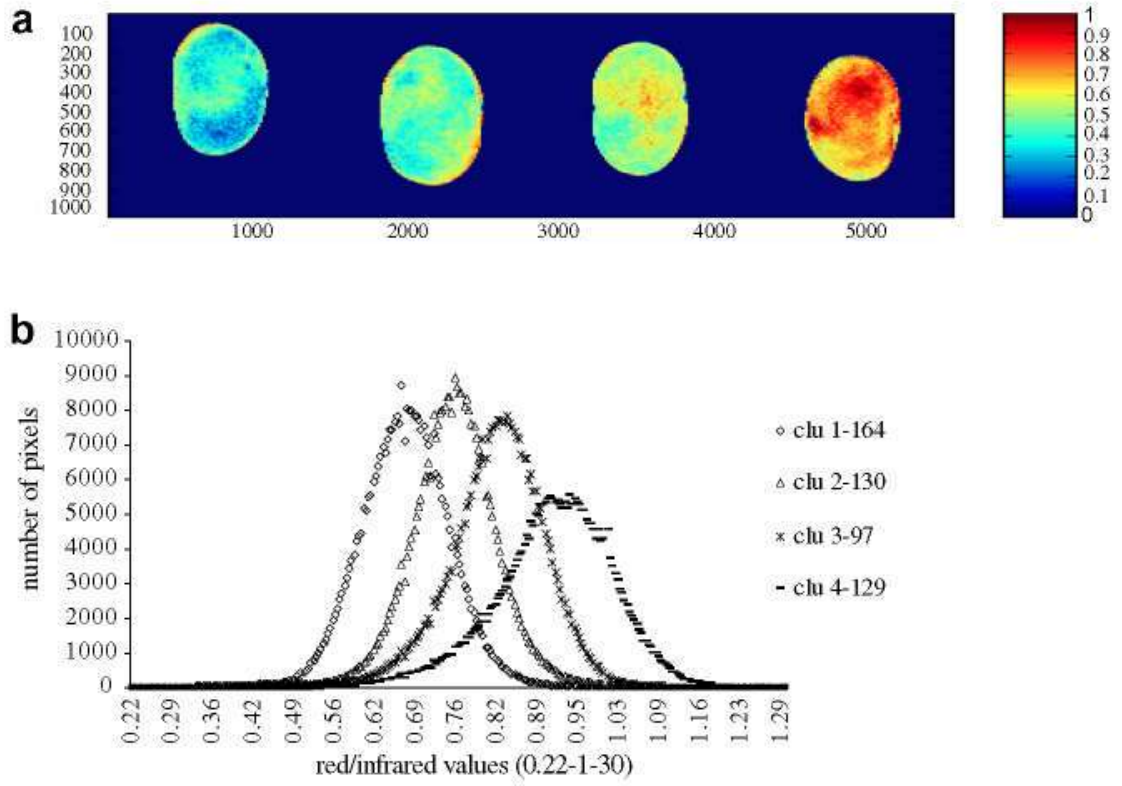

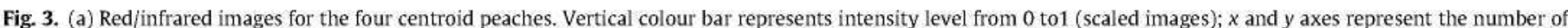

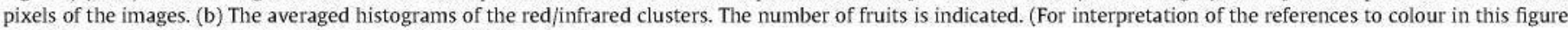
legend, the reader is referred to the web version of this article.)

Table 1

The number of observations per cluster and cultivar based on Red/InfraRed classification.

\begin{tabular}{llllll}
\hline Cultivar & Cluster 1 & Cluster 2 & Cluster 3 & Cluster 4 & Total \\
\hline Richlady & 138 & 79 & 20 & 3 & 240 \\
Kingcrest & 2 & 7 & 19 & 32 & 60 \\
Unknown & 24 & 39 & 41 & 36 & 140 \\
RubyRich & - & 5 & 17 & 58 & 80 \\
Total & 164 & 130 & 97 & 129 & 520 \\
\hline
\end{tabular}

\section{Results and discussion}

Three main results are presented in this study: classification based on red histograms, classification based on relative red/infra- red histograms and comparison of multispectral categories with regard to reference parameters such as firmness.

\subsection{Non-supervised classification based on red histograms}

The red channel $(R)$ includes a chlorophyll absorption peak at $675 \mathrm{~nm}$. As fruits ripen, reflection increased in this band due to the chlorophyll degradation and so the histogram shifted toward brighter levels. These results are congruent with those of Tu et al. (1995). More recently, Lu and Peng (2006) indicated the feasibility of using backscattered light at $677 \mathrm{~nm}$ to classify firmness. It is important to note that these authors have focused on local backscattering, while the present study made use of direct lighting and global fruit imaging, which are simpler to incorporate as an on-line procedure.

Table 2

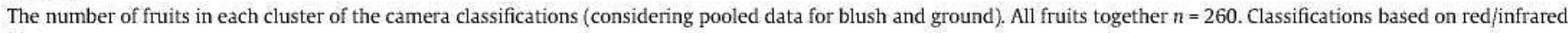
histograms.

\begin{tabular}{|c|c|c|c|c|c|}
\hline \multirow[t]{2}{*}{ Ground color side } & \multicolumn{4}{|c|}{ Blush area side } & \multirow[t]{2}{*}{ Total fruits and percentage } \\
\hline & Cluster 1 & Cluster 2 & Cluster 3 & Cluster 4 & \\
\hline Cluster 1 & 54 & 13 & & & $67(81 \%)$ \\
\hline Cluster 2 & 32 & 28 & 4 & & $64(44 \%)$ \\
\hline Cluster 3 & 9 & 16 & 17 & 2 & $44(40 \%)$ \\
\hline Cluster 4 & 2 & 9 & 32 & 42 & $85(49 \%)$ \\
\hline Total of fruits and its percentage of classification agreement & $97(56 \%)$ & $66(42 \%)$ & $53(32 \%)$ & $44(98 \%)$ & 260 \\
\hline
\end{tabular}

Table 3

Comparison of ANOVA results based on red and red/infrared clustering for the reference parameters.

\begin{tabular}{|c|c|c|c|c|c|c|c|c|}
\hline & & Soluble solids ( ${ }^{\circ} \mathrm{Brix}$ ) & Impact acceleration, $\left(\mathrm{m} / \mathrm{s}^{2}\right)$ & Impact time (ms) & MT firmness $(\mathrm{N})$ & Force/Deformation ( $\mathrm{N} / \mathrm{mm})$ & R 450 & $\mathrm{R} 680$ \\
\hline Red & $F$ (Fisher) & 2.6 & 18.3 & 44.8 & 46.8 & 51,1 & 6,3 & 257 \\
\hline Red/infrared & & 3.9 & 20.3 & 78.4 & 85 & 96,4 & 9,6 & 466 \\
\hline Red & $p$ level & 0.05 & 0 & 0 & 0 & 0 & 0 & 0 \\
\hline Red/infrared & & 0.01 & 0 & 0 & 0 & 0 & 0 & 0 \\
\hline
\end{tabular}


Three or four naturally grouped clusters could be recognized in the fruit samples on the $R$ image histograms using the Ward method (blush and ground color sides). The clusters were numbered from the lowest to the highest mode on the histograms, reflecting increasing maturity levels (i.e. cluster 1 the unripest, cluster 4 the ripest).

Fig. 1 represents the average histogram for each cluster numbered based on expected maturity level. Histograms moved towards higher intensity values for increasing maturity stage. Histograms showed large differences between clusters in the range between 90 and 180 intensity levels. The number of fruits belonging to each cluster is indicated in the figure. A large number $(n=220)$ of fruits were included in the so-called ripest stage.

Fig. 2 shows the images corresponding to the most representative ('centroid') peach for each R cluster and for each channel, red $(675 \mathrm{~nm})$, infrared $(800 \mathrm{~nm})$ and blue $(450 \mathrm{~nm}) . R$ (first line) and $\mathrm{IR}$ images (second line) showed the effect of the shape of the fruit on the global intensity level recorded by the camera; reflectance was higher at the center of the fruit, which was closer and orthogonal to the camera. The blue channel provided very little information compared to the other channels.

\subsection{Combination of red ( $R$ ) and infrared (IR) images for classifications purposes}

In order to compensate for the geometrical effect of the fruit, the R/IR ratio was computed and a new non-supervised classification of the R/IR image histogram (blush and ground color sides) was provided, and the classification computed following Ward method described in Section 2.3. Fig. 3 shows the 'centroid' fruit obtained by means of a rebuilt clustering process that makes use of $R / I R$ images. The corresponding average histograms were more Gaussian as compared to those obtained with $R$ histograms, that is to say the distortion of illumination was avoided.

The number of fruits that belonged to each cultivar and cluster within the R/IR classification is shown in Table 1 . Most cultivars provided fruits for the whole set of maturity stages, only 'Rubyrich' lacked fruits for cluster 1.

In Table 2, a comparison of the agreement of the classifications of the fruits in each R/IR cluster based on the blush and ground color sides is made. Generally, all fruits were classified in the same or adjacent maturity clusters and thus there were a larger number of fruits around the principal diagonal.

In the present case, no relationship was found between multispectral classification and soluble solid content, which is detected by only one NIR band ( $800 \mathrm{~nm}$ ), even though Carlomagno et al. (2004) reported promising results using NIR spectrometry centred on this band. This fact may be explained by the lower range of variability in commercial peaches produced in Murcia, Spain.

Regarding the internal validation of the R/IR classification by means of assignment of a histogram of an image to one of the four clusters whose Euclidean distance was the minimum, the result was that a high percentage of well-classified fruits was obtained, when comparing the observed classification to the predicted classification (90\% of accordance).

\subsection{Comparison of multispectral categories with regard to reference parameters}

The most effective classification method ( $R$ or $R /[R$ ) was determined by comparing the ANOVA analyses of the results for $R$ and R/IR clustering using the reference measurements as shown in Table 3. A major feature was the increase in $F$ (Fisher) value for R/IR clusters as compared to $\mathrm{R}$ clusters for all the parameters tested: soluble solids, impact acceleration, impact duration, Magness-Taylor maximum penetration force, force/deformation ratio, reflec-

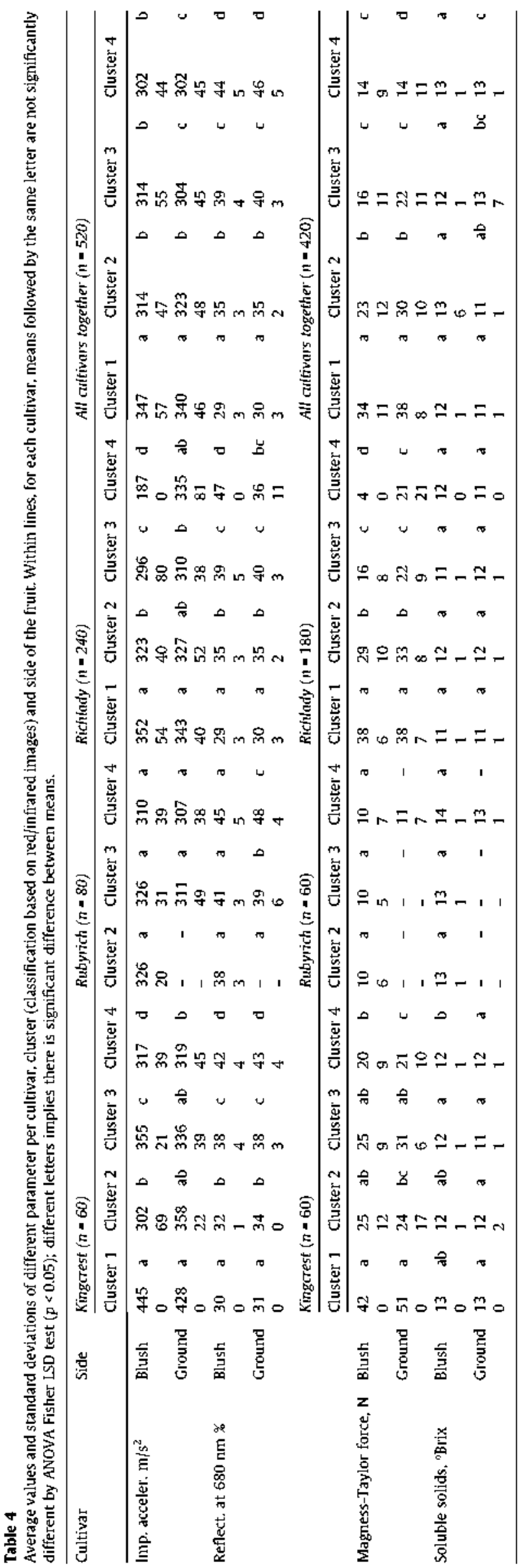


tance at 450 and at $680 \mathrm{~nm}$. The classification capacity of images was improved by the use of relative R/IR images. Reflectance at $680 \mathrm{~nm}$ showed the highest $F$ value in both classifications (466 and 257 for R/IR and R classifications, respectively). This is congruent with the fact that red images and also the relative $R / I R$ images include the chlorophyll absorption peak at $675 \mathrm{~nm}$.

In Table 4, a comparison of the average reference values (soluble solids content, impact acceleration, Magness-Taylor firmness and reflectance at $680 \mathrm{~nm}$ ) for each R/IR cluster and cultivar is made. Considering the pool of the four cultivar samples, firmness and reflectance at $680 \mathrm{~nm}$ varied significantly (significant differences between means for $p$ level below than 0.05) with increasing cluster number: firmness decreased while reflectance at $680 \mathrm{~nm}$ increased. Similar behaviour with respect to firmness and reflectance at $680 \mathrm{~nm}$ was found within each cultivar group except in the case of 'Rubyrich' samples where firmness parameters did not vary with cluster number, and in the case of 'Kingcrest' where variation in Magness-Taylor firmness was erratic for the ground color side. Soluble solids content did not appear to be related to the R/IR classification in any case, showing no significant variation between groups, in accordance with the low range of variability in observed reference values in ${ }^{\circ}$ Brix (between 11 and 13 in averages).

Fig. 4a shows Magness-Taylor firmness vs. impact duration with each point corresponding to one side of the fruit, 420 observations in total. The coefficient of correlation between both measurements $R$ was 0.79 . The standard error of estimation is $8.5 \mathrm{~N}$, being $13.7 \mathrm{~N}$ the standard error of the observed Magness-Taylor firmness in the whole population. A nonlinear relationship was found between Magness-Taylor firmness and Impact response. Such nonlinear behaviour has also been referred to in the literature (Diezma-Igle-

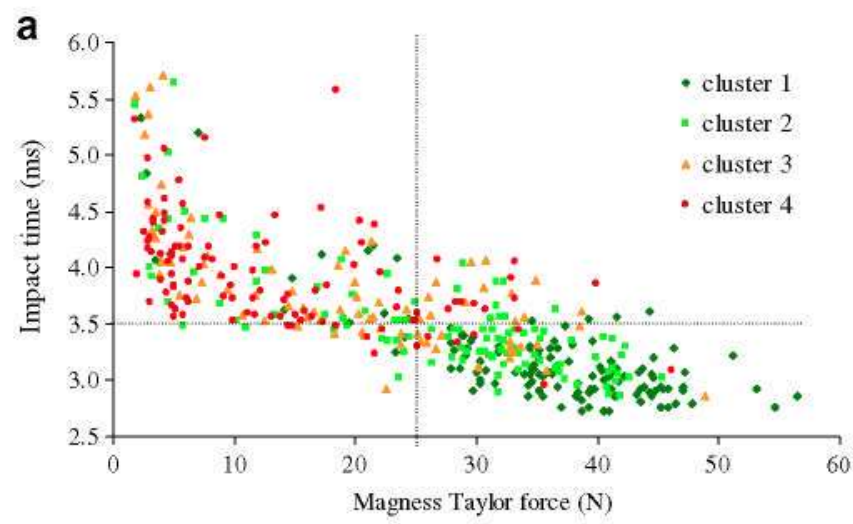

b

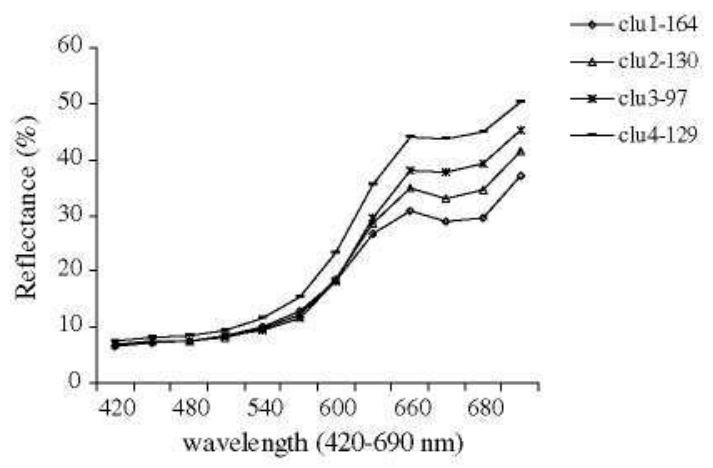

Fig. 4. (a) Magness-Taylor force ( $x$ axis) versus impact time ( $y$ axis). Each point corresponds to one side of the fruit, all measurements $n=420$. (b) Average reflectance visible spectrum (Minolta) for each non supervised cluster of the camera (red/infrared images), $n=520$. (For interpretation of the references to colour in this figure legend, the reader is referred to the web version of this article.) sias et al., 2006). Firmness decreased for an increasing number of clusters (1-4): Magness-Taylor firmness for almost all fruits ( $82 \%$ ) belonging to cluster 4 was less than $25 \mathrm{~N}$ while that for $87 \%$ of fruits from cluster 1 was larger than $25 \mathrm{~N}$.

Fig. 4b shows the average visible reflectance spectrum (420$690 \mathrm{~nm}$ ). In the interval between $630 \mathrm{~nm}$ and $690 \mathrm{~nm}$, the average spectrum consistently increased with maturity cluster; this result is in accordance with the earlier results such as those reported by Ferrer et al. (2005) who also found higher reflectance values in the same range as in more mature peaches.

\section{Conclusions}

With the aim of classifying peaches at harvest into maturity levels, two multispectral camera classification procedures were established using red channel (red images, R) and a combination of red and infrared images (red divided by the corresponding infrared image, R/IR). The use of the R/IR ratio avoided the effect of fruit shape on light reflectance and thus improved the definition of multispectral maturity clusters. Both classification procedures (applied to the histograms of $R$ and R/IR images, respectively) consistently showed increasing harvest maturity levels, from clusters 1 to 4 , compared with firmness (which decreases with maturity level) and reflectance visible spectrum (which increased with maturity in the interval $420-690 \mathrm{~nm}$ ). Image-based classification gave information similar to that obtained from the reflectance at $680 \mathrm{~nm}$ as measured with a portable spectrometer. Reflectance at $680 \mathrm{~nm}$ increased whereas firmness decreased, for increasing maturity levels from clusters 1 to 4 , by considering all data together ( $n=420$ of three cultivars, 'Kingcrest', 'Rubyrich' and 'Richlady'). The image classification did not reflect variation in soluble solids content in accordance with the observed range of variability of the reference values in ${ }^{\circ}$ Brix. In the near future, a combination (fusion) of nondestructive methods of standardizing firmness such as impact and multispectral image data, will improve the classification of peaches at harvest. Finally the nonlinear relationship between Magness-Taylor firmness and impact has been confirmed.

\section{Acknowledgements}

This research was carried out in the Universidad Politécnica de Madrid (Spain) and the program TAGRALIA was funded by Madrid Regional Government.

\section{References}

Aleixos, N., Blasco, J., Navarrón, F., Moltó, E., 2002. Multispectral inspection of citrus in real-time using machine vision and digital signal processors. Computers and Electronics in Agriculture 33 (2), 121-137.

Aleixos, N., Blasco, J., Gómez, J., Moltó, E., 2007. Citrus sorting by identification of the most common defects using multispectral computer vision. Journal of Food Engineering 83 (3), 384-393.

Carlomagno, G., Capozzo, L., Attolico, G., Distante, A., 2004. Non-destructive grading of peaches by near-infrared spectrometry. Infrared Physics \& Technology 46 (12), 23-29.

Delwiche, M., Tang, S., Rumsey, J., 1987. Color and optical properties of clingstone peaches related to maturity. American Society of Agricultural Engineers 30, 1873-1879.

Diaz, R., Faus, G., Blasco, M., Blasco, J., Moltó, E., 2000. The application of a fast algorithm for the classification of olives by machine vision. Food Research International 33 (3-4), 305-309.

Diaz, R., Gil, L., Serrano, C., Blasco, M., Moltó, E., Blasco, J., 2004. Comparison of three algorithms in the classification of table olives by means of computer vision. Journal of Food Engineering 61 (1), 101-107.

Diezma-lglesias, B., Valero, C., García-Ramos, F.J., Ruiz-Altisent, M., 2006. Monitoring of firmness evolution of peaches during storage by combining acoustic and impact methods. Journal of Food Engineering 77 (4), 926-935.

Du, C.-J., Sun, D.-W., 2006. Learning techniques used in computer vision for food quality evaluation: a review. Journal of Food Engineering 72 (1), 39-55.

Ferrer, A., Remón, S., Negueruela, A.l., Oria, R., 2005. Changes during the ripening of the very late season Spanish peach cultivar Calanda: feasibility of using CIELAB coordinates as maturity indices. Scientia Horticulturae 105 (4), 435-446. 
García-Ramos, F.J., Ortiz-Cañavate, J., Ruiz-Altisent, M., Díez, J., Flores, L., Homer, I. Chávez, J.M., 2003. Development and implementation of an on-line impact sensor for firmmess sensing of fruits. Journal of Food Engineering 58 (1), 5357.

Gómez-Sanchís. J. Moltó, E Camps-Valls, G Gómez-Chova, L Aleixos, N. Blasco J. 2008. Automatic correction of the effects of the light source on spherical objects. An application to the analysis of hyperspectral images of citrus fruits. Journal of Food Engineering 85 (2). 191-200.

Jahns, G., Nielsen, H.M., Wolfgang, P., 2001. Measuring image analysis attributes and modelling fuzzy consumer aspects for tomato quality grading. Computers and Electronics in Agriculture 31 (1), 17-29.

Kondo, N. Ahmada, U., Montaa, M., Muraseb, H., 2000. Machine vision based quality evaluation of lyokan orange fruit using neural networks. Computers and Electronics in Agriculture $29(1-2), 135-147$.

Kleynen, O., Leemans, $V_{\text {. }}$ Destain, M.-F., 2003. Selection of the most efficient wavelength bands for 'Jonagold' apple sorting. Postharvest Biology and Technology 30 (3), 221-232.

laykin, 5. Alchantis, V., Fallik, E., Edan, Y., 2002. Jmage-processing algorithms for tomato classification. Transactions of the ASAE 45 (3). 851-858.

Leemans, V., Destain, M.-F., 2004. A real-time grading method of apples based on features extracted from defects. Journal of Food Engineering 61, 83-89.

Leemans, V., Magein, H., Destain, M.-F., 2002. AE - Automation and emerging teclmologies: on-line fruit grading according to their external quality using machine vision. Biosystems Engineering 83 (4), 397-404.

Lu, R. 2004. Multispectral imaging for predicting firmness and soluble solids content of apple fruit. Postharvest Biology and Technology 31 (2), 147157.

lu, R., Peng. Y., 2006. Hyperspectral scattering for assessing peach fruit firmness Biosystems Engineering 93 (2). 161-171.

McGlone, V.A., Abe, H., Kawano, S., 1997. Kiwifnit firmness by near infrared light scattering. Journal of NIR 5pectroscopy 5, 83-89.

Mehl, P.M., Chen, Y.R., Moon, Kim, S., Chan, D.E., 2004. Defect and contamination detection and fruit classification: development of hyperspectral imagin technique for the detection of apple surface defects and contaminations. Journal of Food Engineering 61 (1), 67-81.
Merzlyak, M.N., Solovchenko, A.E., Gitelson, A.A., 2003. Reflectance spectral features and non-destructive estimation of chlorophyll, carotenoid and anthocyanin content in apple fruit. Postharvest Biology and Jechnology 27 (2), 197-211.

Qing, Z., Ji, B., Zude, M., 2007. Predicting soluble solid content and firmess in apple fruit by means of laser light backscattering image analysis. Journal of Food Engineering $82(1), 58-67$

Peng, Y. Lu, R, 2006. Improving apple fruit firmness predictions by effective correction of multispectral scattering images. Postharvest Biology and Teclinology 41 (3), 266-274.

Ruiz-Altisent, M., Leó, L, Riquelme, F., 2006. Instrumental quality assessment of peaches: fusion of optical and mechanical parameters. Journal of Food Engineering 74 (4), 490-499.

Singl, N., Delwiche, M.J., 1994. Machine vision methods for defect sorting stonefruit. Transactions of the ASAE 37 (6). 1989-1997.

Tao, Y., Wen, Z, 1999. An adaptive spherical image transform for high-speed fruit defect detection. Transaction of the ASAE 42 (1), 241-246.

Tu, K., De Busscher, R., De Baerdemaeker, J., Schrevens, E., 1995. Using laser beam as light source to study tomato and apple quality non-destructively, ln: Proceeding of the Food Processing Automation IV Conference, 3-5 November. 1995, Chicago, Il, pp. 528-536.

Unay. D., Gosselin, B., 2006. Automatic defect segmentation of 'Jonagold' apples on multi-spectral images: a comparative study. Postharvest Biology and Technology 42 (3), 271-279.

Vila, J., Calpe. J., Pla, F., Gómez, L., Connell, J., Marchant, J., Calleja, J., Mulqueen, M., Muñoz, J., Klaren, A. SmartSpectra, TheSmartSpectraTeam, 2005. Applying multispectral imaging to industrial environments. Real-Time Imaging 11 (2). $85-98$.

Ward, J.H., 1963. Hierarchical grouping to optimize an objective function. Journal of the American Statistical Association 58, 236-244.

Zheng. C., Sun, D.-W., Zheng, L, 2006. Recent developments and applications of image features for food quality evaluation and inspection - a review. Trends in Food Science \& Technology 17 (12), 642-655.

Zude, M., 2003. Comparison of indices and multivariate models to non-destructively predict the fruit cllorophyll by means of visible spectrometry in apple fruit. Analytica Chemical Acta 481 (1), 119-126. 